\title{
Effects of the Hot Isostatic Pressing Process on Crack Healing of the Laser Repair-Welded CM247LC Superalloy
}

\author{
Keng-Tu Hsu, Huei-Sen Wang *, Hou-Guang Chen and Po-Chun Chen \\ Department of Materials Science and Engineering, I-Shou University, Kaohsiung 84001, Taiwan; \\ bulato1980@yahoo.com.tw (K.-T.H.); houguang@isu.edu.tw (H.-G.C.); john19921120@yahoo.com.tw (P.-C.C.) \\ * Correspondence: huei@isu.edu.tw; Tel.: +886-7-6577711 (ext. 3111); Fax: +886-7-6578444 \\ Academic Editor: Jonathan Cormier \\ Received: 30 July 2016; Accepted: 29 September 2016; Published: 10 October 2016
}

\begin{abstract}
This study investigated the effects of the hot isostatic pressing process on the crack healing, microstructure, and mechanical properties of the laser repair-welded CM247LC precipitation-hardened superalloy. To ensure the strength of the repair-welded area, this study used the direct re-melting approach, and simulated the repair welding with the filler addition, which has a chemical composition matching that of the base superalloy. As expected, different types of cracks, including the solidification crack in the weld fusion zone and various types of liquidation cracks in the heat-affected zone, were observed. Through a proper hot isostatic pressing healing process, all cracks in the weld fusion zone and the heat-affected zone of the repair-welded pieces were healed. At the same time, some nano- and micro-sized carbides tended to form discontinuously along the healed crack trace. A micro-hardness test was conducted in the repair-welded area, and the results were similar to that of the as-cast material.
\end{abstract}

Keywords: laser repair welded; hot isostatic pressing; nickel base superalloy

\section{Introduction}

The CM247LC nickel base superalloy has excellent high temperature strength, hot corrosion resistance, and thermal fatigue resistance. Therefore, it has been extensively used in the aviation and energy industries, commonly as vanes and blades [1-3]. However, during the casting process or after service, some non-critical defects on the surface of the cast may arise. As the cost of CM247LC cast is high, the defects that occur in a non-fatal position are likely to be scraped and repaired by welding.

A low energy input and high energy density Nd:YAG laser repair welding technique has been discussed extensively in recent years [4-6]. It is used to partially solve the problem of the formation of numerous cracks $[7,8]$ in the traditional tungsten inert gas repair welding technique. However, the high power density and low energy input characteristics of the Nd:YAG laser welding heat or cool the alloy more rapidly, as compared to other traditional welding processes, thus resulting in non-equilibrium $[7,8]$. When non-equilibrium occurs, this promotes the localized liquation of the phase interface (the $\gamma^{\prime}$ phase interface, carbide interface, or $\gamma+\gamma^{\prime}$ eutectic phase interface) in the heat-affected zone (HAZ) during the heating process. In the subsequent cooling process, greater thermal stresses and solidification shrinkage strains in the HAZ are exhibited, which encourage the cracks originating from the HAZ liquation to propagate along the grain boundaries into the weld fusion zone (WFZ) [9]. However, as they are located below the WFZ, these kinds of cracks are difficult to observe directly.

In comparison to the well-known low $\mathrm{Al} / \mathrm{Ti}$ superalloy, such as IN718, CM247LC is a precipitation-hardened nickel base superalloy with high $\mathrm{Al} / \mathrm{Ti}$ contents. If a homogeneous filler wire (e.g., CM247LC) is used, solidification cracks are more likely to occur in the WFZ. In view of this, the solid 
solution-strengthening nickel base superalloy (e.g., IN-625) [10-13] filler wire, which has a lower strength, is generally used as a filler wire for repair welding. While the solid solution-strengthening nickel base filler wire contributes to reducing the probability of WFZ cracks, the strength of the repair-welded zone is not as good as that of the original parent material (PM), hence influencing the overall cast fatigue resistance. Therefore, the HAZ liquation crack and the under-strength of the repair-welded zone become two major problems for the present laser repair welding technique.

According to previous literature [14], the hot isostatic pressing (HIP) technique is often used to eliminate the voids and pores in a cast, and more recently, it has been used for healing the cracks in laser deposition [15]. Therefore, in order to confirm the feasibility of the HIP crack healing technique in homogeneous filler wire repair welding, this study used the preselected laser welding parameters for direct laser surface remelting of CM247LC (simulated homogeneous filler wire for repair welding). When various cracks are produced, an IN-625 filler wire is employed for surface sealing before HIP. HIP healing is then implemented under preselected HIP parameters. After the HIP process, the microstructure and crack healing in the various positions of the PM, WFZ, and HAZ of the test pieces are observed, and the mechanical properties are tested.

\section{Experimental Procedure}

The material used in this study was the as-cast CM247LC nickel base superalloy (see comparison in Table 1). The experimental sample was a rectangular plate (30 $\mathrm{mm}$ long $\times 20 \mathrm{~mm}$ wide $\times 10 \mathrm{~mm}$ thick), machined from an ingot by wire electrical discharge machining (WEDM). The face of the weld was polished with 2000 grit silicon carbide paper, and the laser repair weld was tested with different welding parameters by a Nd:YAG pulsed laser (AL 120, ALPHA Laser, Puchheim, Germany). To obtain a constant welding speed, the welding process was assisted by a semi-automatic trolley with three preselected laser parameters (Table 2). As seen, the difference in magnitude of peak power or energy input was affected by the variety of laser voltage. Due to Condition A parameters, the heat energy power was slightly insufficient, WFZ was too shallow, and HAZ was not obvious. Thus, only Conditions $B$ and $C$ were compared in the subsequent discussion.

In order to simulate homogeneous filler wire repair welding, the direct laser melting process was used for the CM247LC sample surface, where a repair welded zone with a longitudinal repair weld of about $10 \mathrm{~mm}$ in length and about $0.5 \mathrm{~mm}$ in width was generated. After the direct melting process, the inside of the surface crack of the CM247LC may contain gas or impurities, which is adverse to the subsequent HIP healing process. To seal the surface crack, the IN-625 filler wire (Table 1) and preselected repair welding parameters [16] were then used to cover the surface. Finally, the HIP technique was employed to heal the repaired welded zone crack. HIP parameters were set according to the related references $[17,18]$ and CM247LC thermal properties. The HIP parameters utilized herein were $1180^{\circ} \mathrm{C} / 175 \mathrm{MPa} / 3 \mathrm{~h}$ for the healing tests.

In terms of microstructure observation, cross-sections of the repair welded pieces before and after HIP were cut. After grinding and polishing, an electrolytic corrosive liquid of 70\% phosphoric acid was used for etching. The surface and crack of the repair welded samples were initially observed through an optical microscope (OM, Olympus BX51M, Olympus, Tokyo, Japan). The crack, microstructure changes, and composition changes in WFZ and HAZ were observed through a Scanning Electron Microscopy (SEM, Hitachi S-4700, Hitachi High-Technologies Corporation, Tokyo, Japan) and Energy Dispersive Spectrometer (EDS, HORIBA 7200-H, HORIBA, Ltd., Kyoto, Japan). In order to accurately correspond to various zones in the welds, this study used micro-hardness (Vickers, Shimadzu HMV-2, Shimadzu Corporation, Kyoto, Japan) testing with a $0.3 \mathrm{~kg}$ load.

Table 1. Chemical compositions of CM247LC and IN-625 (wt \%).

\begin{tabular}{cccccccccccccc}
\hline Item & Ni & W & Co & $\mathbf{C r}$ & $\mathbf{A l}$ & Ta & Hf & Ti & Mo & Nb & Mn & Si & C \\
\hline CM247LC & bal & 9.5 & 9.2 & 8.1 & 5.6 & 3.2 & 1.4 & 0.7 & 0.5 & - & - & - & 0.07 \\
IN-625 & bal & - & 1 & 23 & 0.4 & - & - & 0.4 & 10 & 4.15 & 0.5 & 0.5 & 0.1 \\
\hline
\end{tabular}


Table 2. Repair welding parameters adopted in this experiment.

\begin{tabular}{ccccccc}
\hline Conditions & $\begin{array}{c}\text { Laser Voltage } \\
(\mathbf{V})\end{array}$ & $\begin{array}{c}\text { Peak Power } \\
\mathbf{( K W )}\end{array}$ & $\begin{array}{c}\text { Pulse Duration } \\
\mathbf{( m s )}\end{array}$ & $\begin{array}{c}\text { Spot Size } \\
(\mathbf{m m})\end{array}$ & $\begin{array}{c}\text { Frequency } \\
\mathbf{( H z )}\end{array}$ & $\begin{array}{c}\text { Speed } \\
(\mathbf{m m} / \mathbf{m i n})\end{array}$ \\
\hline A & 160 & 0.7 & 4.6 & 0.6 & 14 & 60 \\
B & 170 & 1.0 & 4.6 & 0.6 & 14 & 60 \\
C & 180 & 1.3 & 4.6 & 0.6 & 14 & 60 \\
\hline
\end{tabular}

\section{Results}

\subsection{Microstructure Observations of the PM before and after HIP}

The microstructure of the as-cast CM247LC consists of the precipitation-strengthened phase $\gamma^{\prime}$, $\gamma$ phase, carbides, and non-equilibrium eutectic $\gamma+\gamma^{\prime}$ [19]. When the CM247LC is treated by HIP, an obvious coarsening of the $\gamma^{\prime}$ structure is observed, and the size increases from $0.3 \sim 0.5 \mu \mathrm{m}$ (Figure 1a) to $1.0 \sim 1.5 \mu \mathrm{m}$ (Figure 1b). As the HIP operating temperature does not exceed the solid solution temperature [17] of the material, and the temperature is reduced slowly by furnace cooling, the $\gamma^{\prime}$ particles grow [20].

The carbon content of the as-cast CM247LC is only $0.07 \mathrm{wt} \%$, and thus there are relatively fewer carbides. The EDS compositional analysis shows that carbides in the as-cast CM247LC are predominantly the MC type (Figure 1c), enriched in Hf and Ta. After HIP healing, the originally concentrated blocky carbide is gradually decomposed into smaller fine needles (Figure 1d).

The $\gamma+\gamma^{\prime}$ eutectic phase in the as-cast CM-247LC (Figure 1e) is usually the product of micro-segregation in the final solidification process of casting, which is distributed on a grain boundary. With the combination of high pressure and high temperature during the HIP process, the proportion of the eutectic structure (Figure 1f) is gradually reduced.

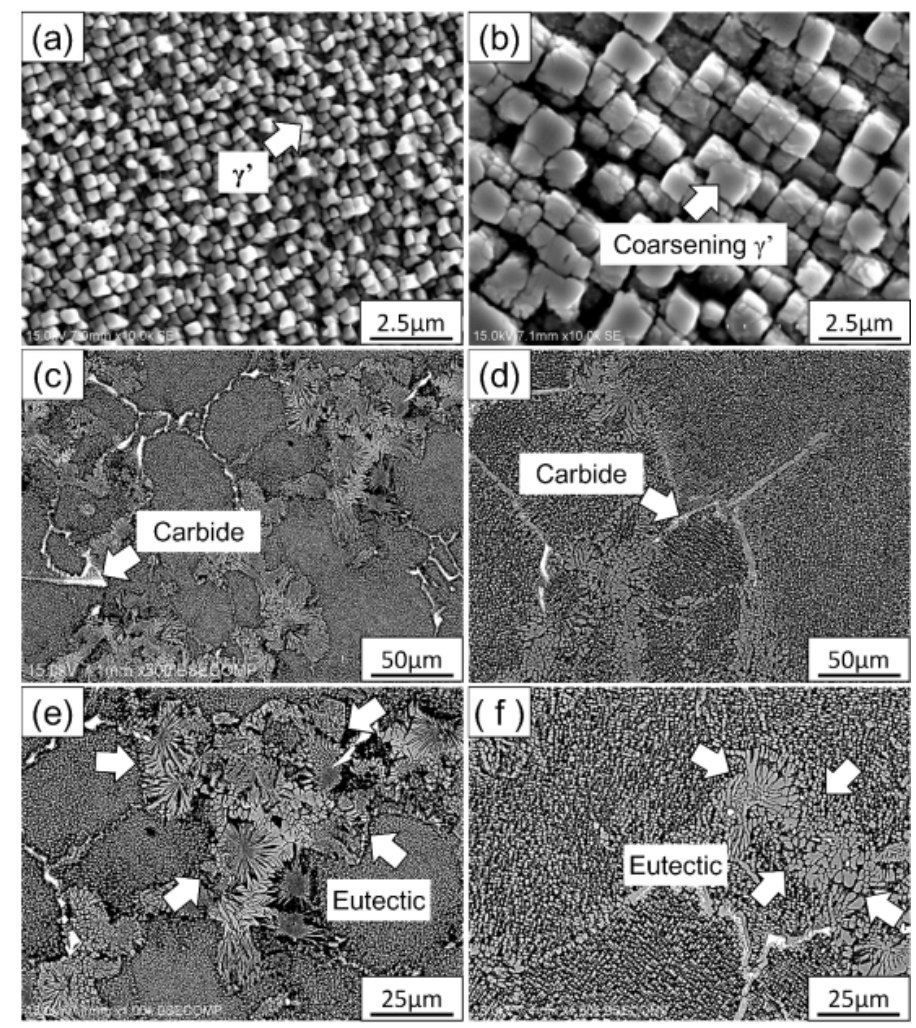

Figure 1. Microstructure of as-cast CM247LC before or after the HIP process: $(\mathbf{a}, \mathbf{b})$ are $\gamma^{\prime} \mathbf{s},(\mathbf{c}, \mathbf{d})$ are carbides, and $(\mathbf{e}, \mathbf{f})$ are eutectics. Here, $(\mathbf{a}, \mathbf{c}, \mathbf{d})$ are obtained before the HIP process, while $(\mathbf{b}, \mathbf{d}, \mathbf{f})$ are obtained after the HIP process. 


\subsection{Microstructure and Crack Observations after CM247LC Laser Direct Melting}

CM247LC is a precipitation-strengthened nickel base superalloy that has an Al+Ti content exceeding $6 \mathrm{wt} \%$. When a laser direct melting is conducted, various cracks (Figure 2a-f) are likely to occur during the solidification process. It is observed that in Figure 2a,b in Condition B or C, there are varying degrees of surface cracks and solidification cracks in WFZ, and that partial solidification cracks extend along the grain boundary from HAZ which penetrate directly through WFZ to the surface layer.

In terms of HAZ, it is observed that the $\gamma^{\prime}$ particles in the zone are slightly coarsened (Figure 2c). Moreover, the $\gamma^{\prime}$ particles have a preliminary edge liquation and merge, which may influence the mechanical properties.

As stated above, the Nd:YAG laser is characterized by low energy input and high energy density. When the laser process ends, under the effect of quick cooling and an excessive temperature gradient, the HAZ cracks involved in the various liquation cracks derived from the eutectic phases (Figure 2d), MC-type carbide (Figure 2e), and the intergranular phase (Figure 2f) are easily found in the welds.

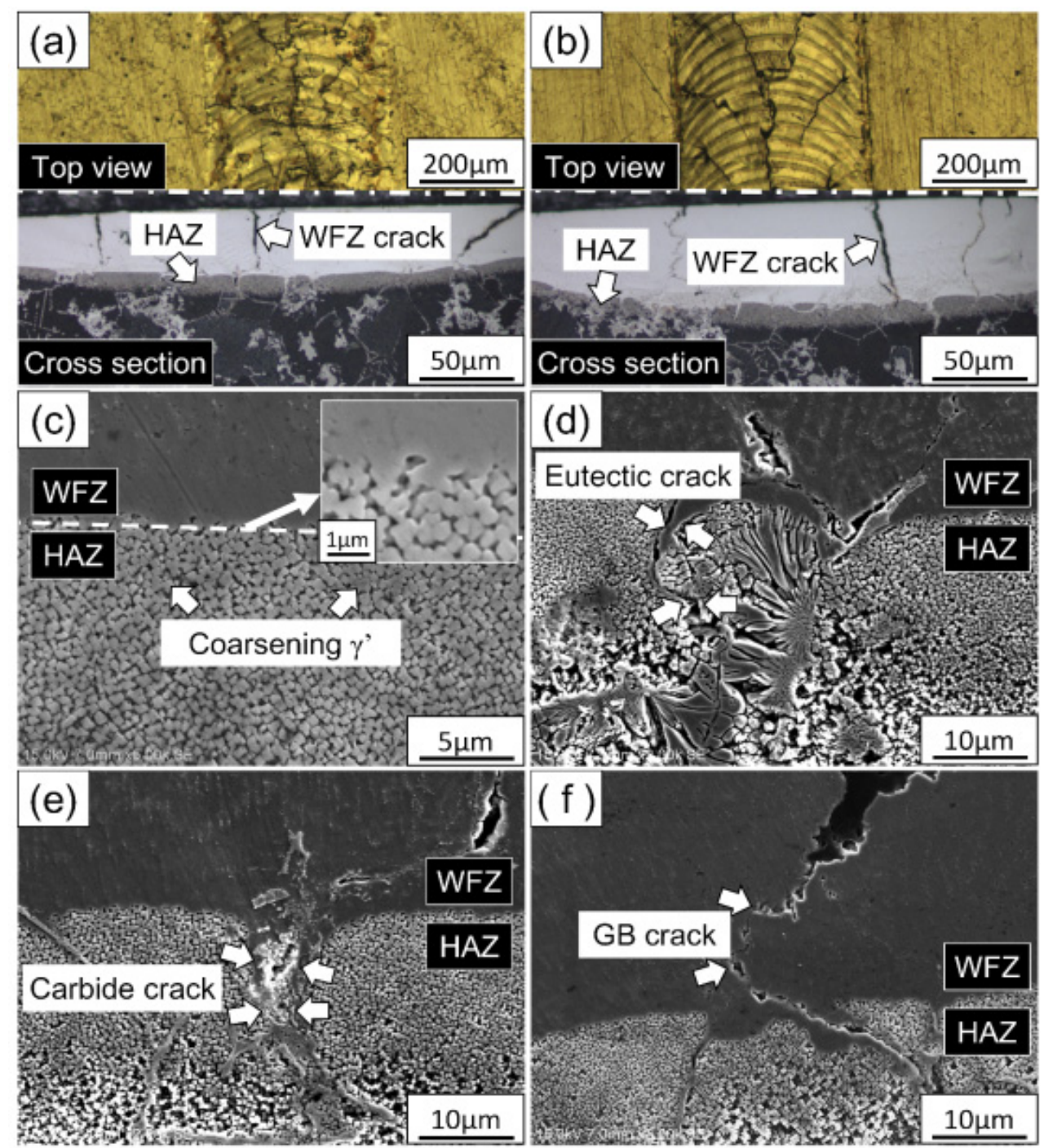

Figure 2. Crack observation on the surface and cross-section of (a) Condition B, (b) Condition C, and (c) HAZ observation of Condition B. Various liquidation cracks, including (d) eutectic, (e) carbide, and (f) grain boundary cracks, are observed in HAZ of Condition B. 


\subsection{Microstructure Observation after IN-625 Surface Sealing}

In this study, the IN-625 filler wire is used to seal the surface of the CM247LC WFZ. According to the microscopic cross-section observations, such as in Condition B (Figure 3a), a small part of the IN-625 and the original CM247LC are mixed, and no surface cracks are found on the top of WFZ (TWFZ). However, in this stage both the original CM247LC solidification crack at the bottom of the WFZ (BWFZ) (Figure 3a,b) and the liquation crack in the HAZ (Figure 3b,c) still exist, which will be eliminated by the subsequent HIP healing technique.
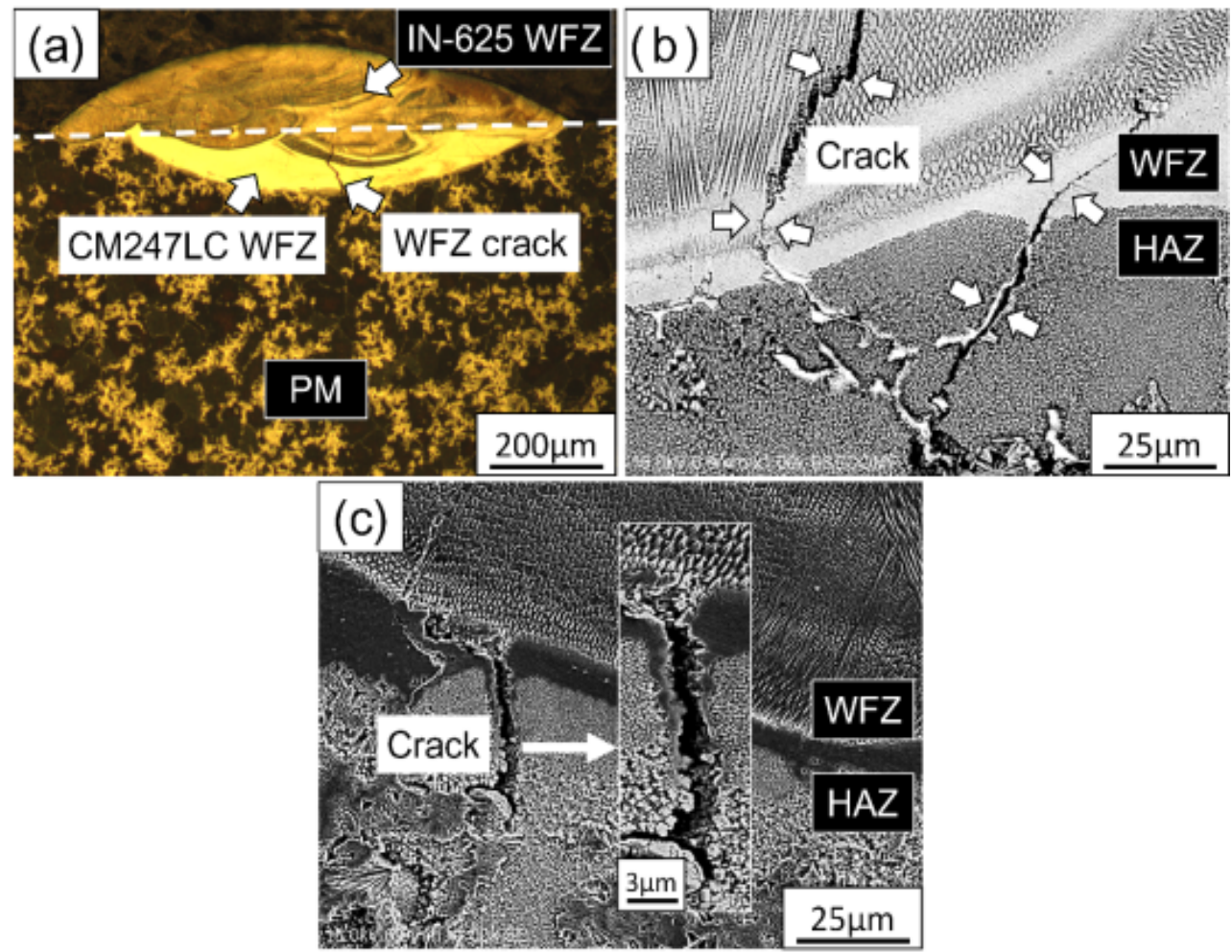

Figure 3. (a) IN-625 sealing on the top. Various cracks were still observed in (b) bottom of WFZ, or in (c) HAZ.

\subsection{Microstructure and Crack Observations after the HIP Healing Process}

After the $3 \mathrm{~h}$ high temperature and high pressure HIP process, various solidification cracks or liquation cracks in Condition B and Condition C (Figure 4a-d) have completely healed [14]. However, after the HIP process, different zones (Figure 4e) are observed in the WFZ of the repaired welded piece: TWFZ, partial mixed zone (PMZ) and WFZ un-mixed zone (WFZ-UMZ) [16], and BWFZ and HAZ (Figure 4f). The HAZ resulting from WFZ overlapping is not obviously seen.

WFZ-UMZ (Figure 4e) is a peculiar structure zone resulting from the laser repair welding. Due to the low energy and very fast cooling of the laser process, when a IN-625 filler wire is used for surface sealing, the filler wire may preferentially absorb the majority of the laser energy [16], whereas while the residual energy is enough to melt part of the CM247LC re-melting zone, it is insufficient to mix with the IN-625 filler wire, thus presenting a stagnated state. WFZ-UMZ is formed during the subsequent instantaneous solidification [21,22].

Figure 5a-d shows EDS linescan (including Mo (Figure 5b), Co (Figure 5c), and Al (Figure 5d) composition profiles) across BWFZ, WFZ-UMZ, PMZ, and TWFZ, suggesting the WFZ-UMZ unmixed the IN-625 filler wire. 
As WFZ-UMZ has rapid cooling during the solidification of the repair welding, the $\gamma^{\prime}$ phase is unlikely to precipitate. However, after the HIP process, the $\gamma^{\prime}$ in this zone is finely and densely precipitated.

After the HIP process, in the HAZ the $\gamma^{\prime}$ particles (Figure 4f) are larger than those before HIP (Figure 4c). Moreover, when compared with the $\gamma^{\prime}$ in the PM (Figure 1b), $\gamma^{\prime}$ in the HAZ is irregular and disordered.

After the HIP process (Figure 4c), some fine particles (approximately submicrons or nanometers in size) exist along the healing trace. The EDS analysis results show that, when compared with the surrounding matrix, the healing trace particles contain rich Hf and Ta elements, indicating that the precipitates are (Hf-Ta)-rich MC carbides [23]. In the HIP healing process, the repair-welded samples are subjected to a high temperature and pressure simultaneously, while the low melting structure $\left(\gamma+\gamma^{\prime}\right)$ is thermodynamically unstable. Therefore, the MC carbide is first formed in the $\gamma+\gamma^{\prime}>\mathrm{MC}+\gamma$ mode [15] on the crack healing trace. Finally, as restricted by the HIP's high pressure, only extra-fine carbide grains are formed and dispersed over the healing trace.
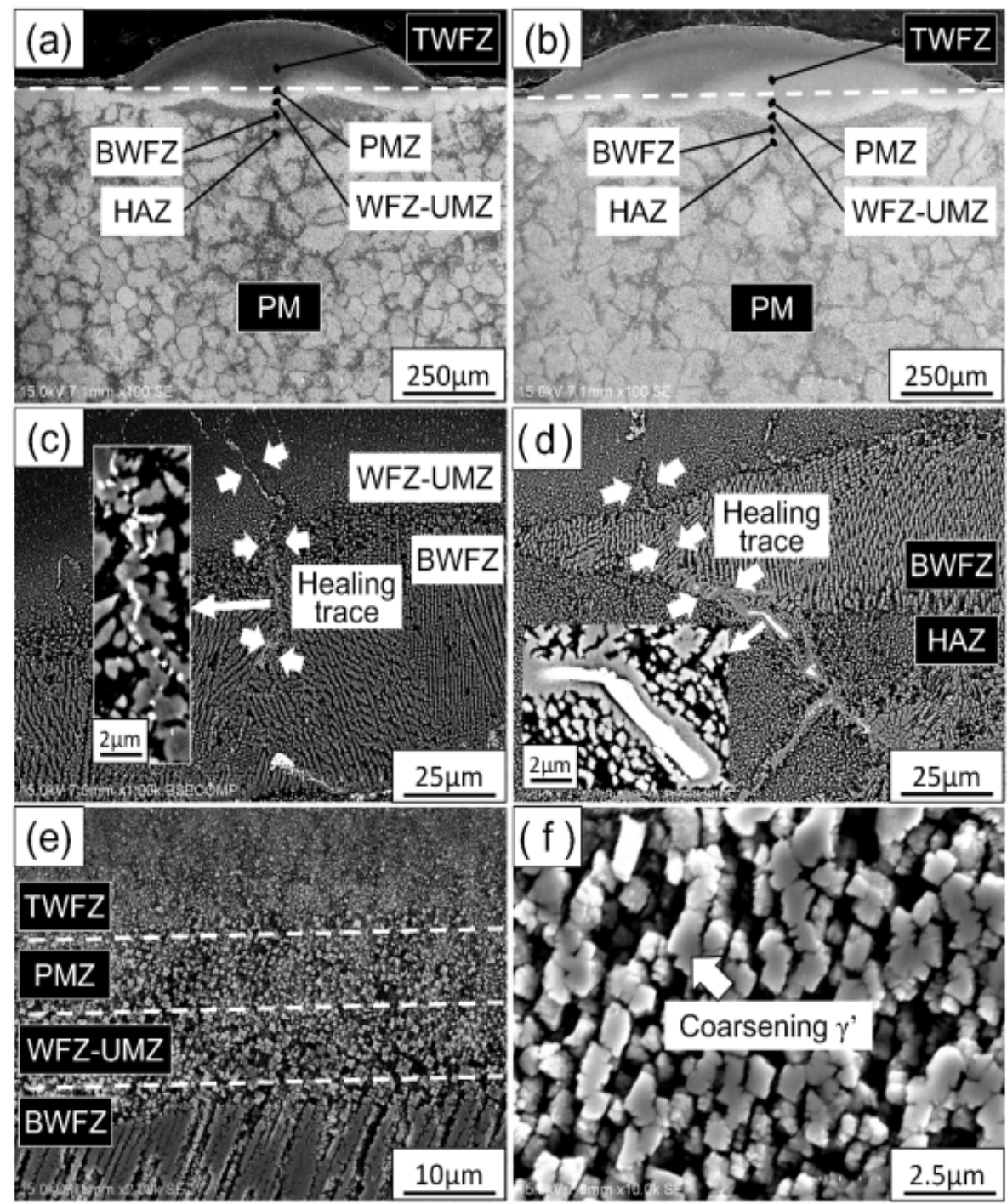

Figure 4. After HIP, an overview of the repair welding under (a) welding Condition B and (b) Condition C, (c) nano- and micro-sized carbides along the healed crack trace, and (d) large-sized carbides after the HIP process. (e) Various regions were observed in WFZ and (f) $\gamma^{\prime}$ in HAZ after the HIP process. 

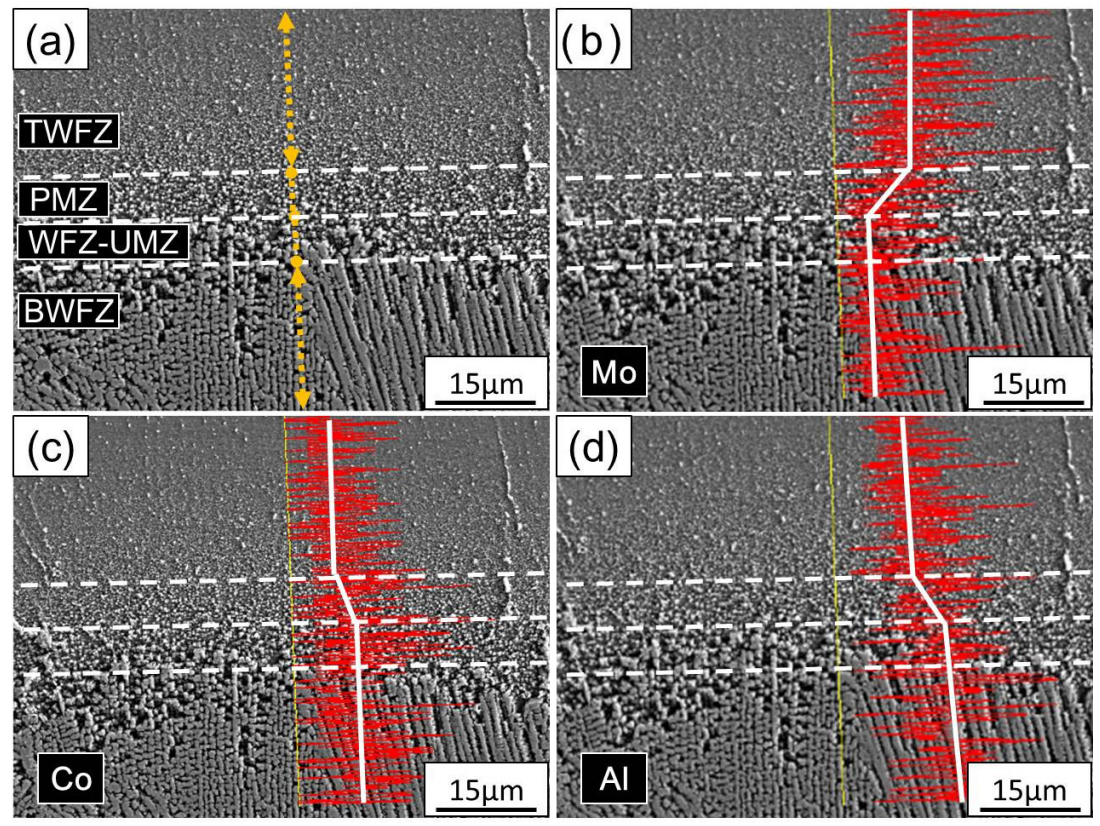

Figure 5. (a) EDS line scan across the various regions in WFZ, with composition profiles including (b) Mo, (c) Co, and (d) Al.

\subsection{Hardness Test before and after HIP}

Figure 6 shows the micro-hardness test for the PM, HAZ, BWFZ, WFZ-UMZ, and TWFZ on the cross-sections of the Condition $B$ and $C$ samples. It is observed that the hardness values of the Condition $\mathrm{B}$ and $\mathrm{C}$ samples exhibit a similar tendency as the measurement position changes, which is discussed as follows.

Before HIP, influenced by the high temperature of the laser process, the $\gamma^{\prime}$ particles in the HAZ are slightly coarsened, and there is initial liquation and then a merger of the irregular shapes (Figure 2c). Therefore, the HAZ hardness is slightly lower than that of the PM. BWFZ and WFZ-UMZ are the original CM247LC laser re-melting zones; BWFZ is displayed in a columnar grain structure along the heat flow and WFZ-UMZ has a very high cooling rate. Thus, the strengthening structure of the $\gamma^{\prime}$ phase does not have enough time to precipitate completely. Therefore, in comparison to PM, the hardness values of the two zones are further reduced. TWFZ is composed of the IN-625 solid solution-strengthening filler wire. In this zone, whether before or after (see Figure 5a) the HIP process, in addition to the $\gamma$ phase matrix, only small-size [16] carbides were observed. This suggests that the zone has a minimum hardness.

After HIP, while the cracks are healed, the $\gamma^{\prime}$ in the PM (Figure 1b) and HAZ (Figure 4f) is further coarsened, so that the hardness of the two zones is slightly lower than that before HIP. The microstructure change after HIP in TWFZ and BWFZ is not obvious, and thus the hardness of the two zones is changed slightly, as compared with that before HIP. However, the hardness of WFZ-UMZ markedly increases, as WFZ-UMZ contains elements similar to the original PM CM247LC (Figure $5 c, d$ ). After the subsequent HIP treatment, the $\gamma^{\prime}$ grains are precipitated, presenting a finer and more complete cubic morphology than that of PM. Hence, the WFZ-UMZ hardness is much higher than that before HIP.

According to the aforementioned hardness test results, after HIP, BWFZ and WFZ-UMZ approach $400 \mathrm{Hv}$, or are higher than $400 \mathrm{Hv}$, which is very close to the PM strength. If the subsequent post-weld heat treatment [24] is conducted, it may further improve the mechanical properties of the repair-welded piece. However, during the post-weld heat treatment, the risk of the stain age cracking [25] can be an additional concern. To fully ensure the feasibility of the proposed repair-weld approach, post-weld heat treatment of the HIP-healed samples should be considered as the future work. 
In this study, the experimental design is a single-pass remelting test to simulate the single-pass filling of a homogeneous filler wire. When a low strength IN-625 filler wire is used for surface sealing, a small PMZ forms in the remelting area. In terms of practical operation, to reduce the effect of the PMZ on the overall repair-welded zone strength, CM247LC filler wire may be used for multi-pass repair welding, in order to thicken BWFZ before surface sealing. After the HIP healing treatment, the TWFZ and PMZ layers are removed, providing sound strength to the repair-welded area. However, during the multipass welding process, the WFZ is thickened; thus, more cracks may be observed, such as in the interlayer between the original and subsequent WFZ. To fully heal the cracks of a thickened weld, the HIP parameters (e.g., temperature, pressure, and soaking time) may need to be adjusted.

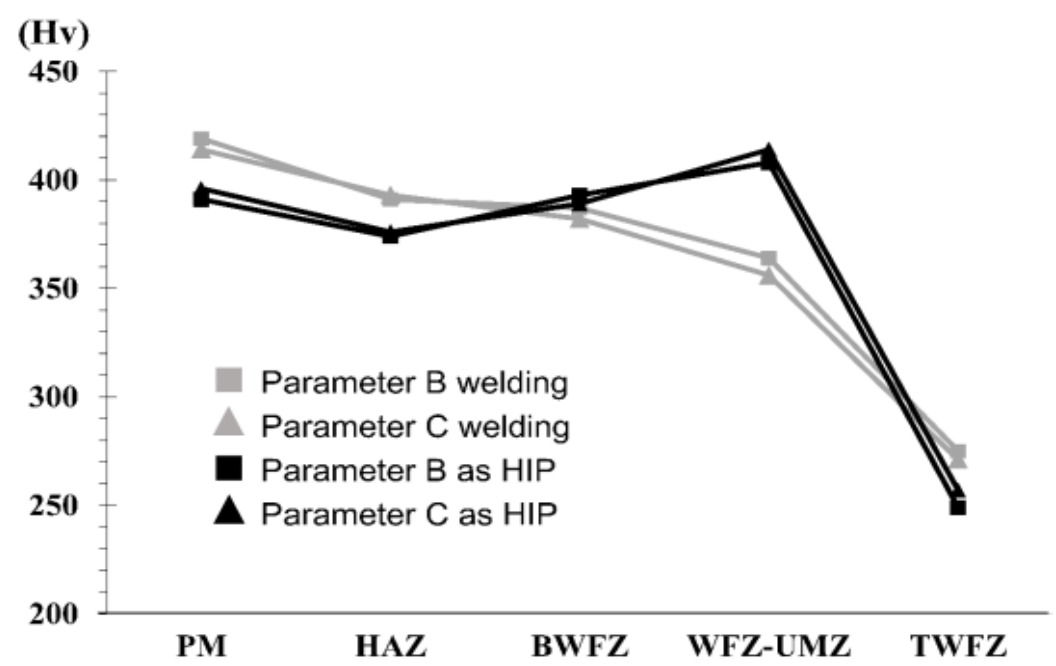

Figure 6. Hardness in the various regions of the repaired welds before and after the HIP processes (Hv).

\section{Conclusions}

Based on results of this study, the conclusions are drawn as follows:

1. Through the proper HIP healing process, all cracks in the WFZ and HAZ of the repair-welded pieces (including repair welding Conditions B and C) were healed.

2. After the HIP healing process, some nano- and micro-sized carbides tended to form discontinuously along the healed crack trace of the repair-welded pieces.

3. After the HIP healing process, the size and volume fraction of the segregation were reduced, thereby improving the reliability and mechanical properties of the superalloy.

4. After the HIP healing process, the hardness in the repair-welded areas (including repair welding Conditions B and C) was improved, and it is similar to that in the PM.

Author Contributions: Keng-Tu Hsu and Huei-Sen Wang conceived and designed the experiments; Keng-Tu Hsu, Huei-Sen Wang, and Po-Chun Chen performed the experiments; Keng-Tu Hsu, Huei-Sen Wang and Hou-Guang Chen analyzed the data; Keng-Tu Hsu and Po-Chun Chen contributed reagents/materials/analysis tools; Keng-Tu Hsu and Huei-Sen Wang wrote the paper.

Conflicts of Interest: The authors declare no conflict of interest.

\section{References}

1. Harris, K.; Schwer, R.E. Vacuum Induction Refining MAR M 247 for High Integrity Turbine Rotating Parts. In Proceedings of TMS-AIME Fall Meeting, St. Louis, MO, USA, 1-11 October 1978.

2. Harris, K.; Schwer, R.E. Vacuum Induction Refined MAR M 247 for Investment Cast Turbine Components. In Proceedings of AVS 6th International Vacuum Metallurgical Conference, San Diego, CA, USA, 7-8 April 1979. 
3. MAR M 247 Derivations-CM 247 LC DS Alloy, CMSX Single Crystal Alloys: Properties and Performance. Available online: http://www.tms.org/superalloys/10.7449/1984/superalloys_1984_221_ 230.pdf (accessed on 8 October 2016).

4. Ding, R.G.; Ojo, O.A.; Chaturvedi, M.C. Laser beam weld-metal microstructure in a yttrium modified directionally solidified $\mathrm{Ni}_{3} \mathrm{Al}$-base alloy. Intermetallics 2007, 15, 1504-1510. [CrossRef]

5. Pang, M.; Yu, G.; Wang, H.H.; Zheng, C.Y. Microstructure Study of Laser Welding Cast Nickel-Based Super Alloy K418. J. Mater. Process. Technol. 2008, 207, 271-275. [CrossRef]

6. Chiang, M.F.; Chen, C. Induction-assisted laser welding of IN-738 nickel-base superalloy. Mater. Chem. Phys. 2008, 114, 415-419. [CrossRef]

7. Ojo, O.A.; Chaturvedi, M.C. On the role of liquated $\gamma^{\prime}$ precipitates in weld heat affected zone microfissuring of a nickel-based superalloy. Mater. Sci. Eng. A 2005, 403, 77-87. [CrossRef]

8. Ojo, O.A.; Richards, N.L.; Chaturvedi, M.C. Contribution of constitutional liquation of gamma prime precipitate to weld HAZ cracking of cast Inconel 738 superalloy. Scr. Mater. 2004, 50, 641-646. [CrossRef]

9. Bonifaz, E.A.; Richards, N.L. Modeling cast IN-738 superalloy gas tungsten arc welds. Acta Mater. 2009, 57, 1758-1794. [CrossRef]

10. Gandy, D.W.; Frederick, G.J.; Peterson, A.J.; Stover, J.T.; Viswanathan, R. Development of a Laser-Based/High Strength Weld Filler Process to Extend Repair Limits on IN-738 Gas Turbine Blades. In Proceedings of the Fourth International EPRI Conference on Welding and Repair Technology for Power Plants, Marco Island, FL, USA, June 2000.

11. Development of an Improved Stainless Steel to Ferritic Steel Transition Joint. Available online: https://app.aws.org/wj/supplement/WJ_1977_11_s354.pdf (accessed on 20 September 2016).

12. Surfacing of $3.25 \%$ Nickel Steel with Inconel 625 by the Gas Metal Arc Welding-Pulsed Arc Process. Available online: https://www.scribd.com/document/247061079/Surfacing-of-3-25-Nickel-steel-withInconel-625-by-the-gas-metal-arc-welding-pulsed-arc-process (accessed on 20 September 2016).

13. GTA Weld Cracking_Alloy 625 to 304L. Available online: https://app.aws.org/wj/supplement/WJ_1985_ 08_s227.pdf (accessed on 20 September 2016).

14. Price, P.E.; Kohler, S.P. Hot Isostatic Pressing of Metal Powders, 9th ed.; ASM International: Materials Park, OH, USA, 1984; Volume 7, pp. 419-443.

15. Zhao, X.M.; Lin, X.; Chen, J.; Xue, L.; Huang, W.D. The effect of hot isostatic pressing on crack healing, microstructure, mechanical properties of Rene88DT superalloy prepared by laser solid forming. Mater. Sci. Eng. A 2005, 504, 129-134. [CrossRef]

16. Wang, H.S.; Huang, C.Y.; Ho, K.S.; Deng, S.J. Microstructure Evolution of Laser Repair Welded René 77 Nickel-Based Superalloy Cast. Mater. Trans. 2011, 52, 2197-2204. [CrossRef]

17. Diffusion Welding of Nickel-based Superalloys. Available online: https://www.scribd.com/doc/314478417/ Diffusion-Welding-of-Nickel-Alloys (accessed on 8 October 2016).

18. Hoppin, G.S., III; Curbishley, G. Dual Alloy Turbine Wheels. U.S. Patent No. 4581300, 8 April 1986.

19. Erickson, G.L. Properties and Selection: Irons, Steels, and High-Performance Alloys, 10th ed.; ASM International: Materials Park, OH, USA, 1989; Volume 1, pp. 981-994.

20. Grosdidier, T.; Hazotte, A.; Simon, A. Precipitation and dissolution processes in $\gamma / \gamma^{\prime}$ single crystal nickel-based superalloys. Mater. Sci. Eng. A 1998, 256, 183-196. [CrossRef]

21. Kou, S. Welding Metallurgy, 2nd ed.; John Wiley \& Sons: Hoboken, NJ, USA, 2003; pp. 303-314.

22. Sims, C.T.; Hagel, W.C. The Superalloys; John Wiley \& Sons: New York, NY, USA, 1972; pp. 513-514.

23. Chen, J.; Lee, J.H.; Jo, C.Y.; Choe, S.J.; Lee, Y.T. MC carbide formation in directionally solidified MAR-M247 LC superalloy. Mater. Sci. Eng. A 1998, 247, 113-125. [CrossRef]

24. Erickson, G.L.; Harris, K.; Schwer, R.E. Directionally Solidified DS CM 247 LC Optimized Mechanical Properties Resulting from Extensive $\gamma^{\prime}$ Solutioning. In Proceeding of Gas Turbine Conference and Exhibit, Houston, TX, USA, 1-10 March 1985.

25. Kayacan, R.; Varol, R.; Kimilli, O. The effects of pre and post weld heat treatment variables on the strain age cracking in welded Rene 41 components. Mater. Res. Bull. 2004, 39, 2171-2186. [CrossRef]

(C) 2016 by the authors; licensee MDPI, Basel, Switzerland. This article is an open access article distributed under the terms and conditions of the Creative Commons Attribution (CC-BY) license (http://creativecommons.org/licenses/by/4.0/). 